\title{
Implementing Activity-Based Costing in the Telecommunications Sector: A Case Study
}

\section{Maria Joao Major*}

Associate Professor of Management Accounting at ISCTE - University Institute of Lisbon and BRU/UNIDE researcher, Avenida das Forças Armadas, ISCTE-IUL, 1649026 Lisbon, Portugal

\begin{abstract}
Profound changes have affected the European telecommunications sector in the last 15 years. With its liberalization at the end of 1990s many telecommunications companies, such as 'International Telecom' had to adopt advanced managerial accounting systems that could provide them with detailed and accurate cost accounting information. To this respect Activity-based Costing revealed crucial to aid International Telecom to face fierce competition coming out from the new operators that came into market and to respond to regulatory demands.
\end{abstract}

Keywords: European telecommunications; Activity-based Costing; Managerial Accounting

\section{Introduction}

This paper aims to investigate how the introduction of competition into the EU telecommunications market affected the development of managerial accounting systems in a specific company called 'International Telecom'. 'International Telecom' was established in the beginning of 1900s to provide telegraphic radio communications. Since then the company has the long distance telecommunications services as its core business. Until the liberalisation of the EU telecommunications sector 'International Telecom' operated in a monopoly regime. This made it a very profitable company. Yet the introduction of competition into the sector in 2000 led to a decrease in 'International Telecom's' turnover, margins, and profits, which pressured it into initiating a full programme of change. This programme of change included: (i) revision of its strategic plan; (ii) adoption of strategic control benchmarks; (iii) implementation of a new career evaluation system; (iv) adoption of EIS - Executive Information Systems to provide senior managers with operational and strategic information; (v) introduction of SAP; and (vi) replacement of 'International Telecom's' previous managerial accounting system by activity-based costing (ABC). Of all the managerial projects introduced, the adoption of $A B C$ was the major one, not only in terms of human and financial resources allocated but also by the time and importance managers attached to the project. ABC was adopted by 'International Telecom' as a management tool to assist managers reducing costs and improving competitiveness (see Jones and Dugdale, 2002 who discuss the relevance of $\mathrm{ABC}$ ). The adoption of a modern and sophisticated managerial accounting system, such as $\mathrm{ABC}$, was needed to assure public opinion, including the regulators and the new operators in the market, that costs were calculated based on a rational and reliable system, and furthermore that 'International Telecom' was making serious efforts to improve its performance.The paper is structured as follows: section two describes 'International Telecom's' managerial accounting system before the liberalisation of the EU telecommunications market; section three discusses how $\mathrm{ABC}$ was implemented and how it operates; the paper ends with the presentation of conclusions in section four.

\section{'International Telecom's' managerial accounting system before liberalisation}

When 'International Telecom's' managers were faced with the prospect of competition being introduced in the EU telecommunications market $[1,2]$ they were not concerned in having a very sophisticated managerial accounting system yet cost objects were already identified.

${ }^{1} \mathrm{~A}$ disguised name is used in the paper to cover up the real identity of the company.
Direct costs were calculated for each of these cost objects, and indirect costs were allocated proportionally to the amount of direct costs. Direct costs were the most important element in total costs, representing $70 \%$ on average of total costs. It was decided that cost objects should be the products and services the company was providing. Those were: (1) automatic international fixed phone calls (for Europe, US, Canada, Central America, Brazil, South America, Angola, South Africa, other African countries and Asia); (2) 'International Telecom' Phone Card; (3) International 'Green Calls'; (4) Virtual Private Network; (5) Country Direct; (6) Value Added Services; (7) Semi-Automatic Calls; (8) Intercontinental Telex; (9) International Telegraphy Services; (10) Data Communication; (11) Store \& Forward Fax; (12) TV; (13) Radio; (14) Video-Communications; (15) Les/Inmarsat C; (16) Leased Circuits; (17) TCR; (18) Restoring; (19) Leased Capacities and (20) Engineering Services.

Direct costs were identified as follows: (1) traffic costs (i.e. the costs 'International Telecom' supports for using the telecommunications capacities of international operators and correspondents); (2) leased capacities (costs of getting basic transport infrastructure to wholesale and retail services); (3) transmission costs (costs that 'International Telecom' supports for using its own systems of submarine cables, satellite, radio, and network); (4) commutation costs (costs of managing the network); (5) other costs of operation (including costs of activities such as engineering, maintenance, management and control, planning, computer systems, training services etc., when these are developed for specific products/services; (6) commercial costs (marketing costs, and other costs related to the commercial function when concerned with specific products/services); and (7) direct costs of capital (costs of capital of the specific fixed assets used to obtain products/services).

Indirect costs were on average roughly $30 \%$ of total costs and comprised the following items: (1) costs of capital not specific to any fixed asset used to obtain products/services; (2) costs of activities not directly associated with cost objects; (3) costs of transmission

*Corresponding author: Maria Joao Major, Associate Professor of Management Accounting at ISCTE-University Institute of Lisbon and BRU/ UNIDE researcher, Avenida das Forças Armadas, ISCTE-IUL, 1649-026 Lisbon, Portugal, Tel: 351/217903495; E-mail: maria.joao.major@iscte.pt

Received November 28, 2013; Accepted December 30, 2013; Published January 06, 2014

Citation: Major MJ (2014) Implementing Activity-Based Costing in the Telecommunications Sector: A Case Study. J Telecommun Syst Manage 3: 111. doi:10.4172/2167-0919.1000111

Copyright: (ㅇ 2014 Major MJ. This is an open-access article distributed under the terms of the Creative Commons Attribution License, which permits unrestricted use, distribution, and reproduction in any medium, provided the original author and source are credited. 
of systems whose capacity was not used; and (4) costs generated by staff departments and costs of macro-structure. Exhibit 1 shows a typical Income Statement prepared for cost accounting reports by 'International Telecom's' management accountants before the adoption of $\mathrm{ABC}$.

Cost accounting reports were prepared by the Finance and Administration Department every quarter, half-year and year. These reports had two parts. The first part provided an income statement for the whole of 'International Telecom', followed by comments and analysis of each main cost/profit item. These comments and analyses would usually not exceed 12 pages. In the second part, income statements were presented by cost object. These reports were prepared basically for the Board of Directors and the managers of the different departments of the company. A standard costing system was used: standard costs were compared with actual costs, and variances were calculated periodically. These variances were used as information for managers, and not for assessments of managerial performance. Cost standards were updated annually. However, by 1996, the existing managerial accounting system was no longer satisfying the costing needs of the company. In 1997 'International Telecom' abandoned this costing system and replaced it with $\mathrm{ABC}$.

\section{Activity-based costing adoption}

$\mathrm{ABC}$ implementation was strongly supported from the beginning by 'International Telecom's' Board of Directors. The Board of Directors had a consensus about the importance of implementing $A B C$, which facilitated its implementation. Substantial material resources, including time and personnel, were allocated to the project. Due to competitive pressures, the information needs of commercial departments (Consumer Markets Department and Carrier Services \& Network Planning Department), together with those imposed by regulators, were identified as a priority. 'International Telecom' began the process of ABC implementation with external consultants in July 1997. The consultants and 'International Telecom's' management accountants decided to adopt a full installation strategy and to implement $A B C$ throughout the whole organisation [3,4].They also decided that in a first phase the $A B C$ system should operate simultaneously with the 'old' managerial accounting system, and that after a short test period it should replace the previous system. Additionally, it was planned that $\mathrm{ABC}$ would be integrated with financial accounting. Finally, they devised an $\mathrm{ABC}$ system to report historical costs.

The consultants took six main steps to implement ABC: (1) selection of teams; (2) team training; (3) definition of activities; (4) definition of the conceptual model; (5) collection of data, and (6) definition of the ABC software. Exhibit 2 traces these six steps over time (Exhibit 2).

In July 1997, teams were selected and trained. From July to September, activities were identified. The ABC model was devised in September. Inputs of $A B C$ and data were obtained from September to December 1997. In December, the software to support the ABC system was chosen. In March 1998, the 1997 accounts were provided by ABC. The consultants formed two committees to support the ABC implementation process. The first consisted of the general finance director and the directors of operational areas (the Finance and Administration, Planning and Control, Consumer Markets, Carrier Services, Telecommunications Infrastructure, and Development and Information Systems departments). The second committee consisted of those responsible for implementing $\mathrm{ABC}$, i.e. the

${ }^{2}$ This includes managers: only the Board of Directors is exempted from this task. ${ }^{3} \mathrm{PMO}$ means 'labour time disclosure'. consultants, 'International Telecom's' management accountants, and representatives of the commercial and production departments. According to the consultants, the idea was for ownership of the system to be shared by all operational departments, and not just the Finance and Administration Department.

After the personnel to implement $\mathrm{ABC}$ had been selected, training programmes were held. They discussed: (1) the design of the ABC model; (2) the objectives behind ABC implementation; and (3) the ABC implementation process. These meetings were directed exclusively at the committee members. It was believed that due to the strategic nature of the ABC system, only those directly involved with the project should shape its objectives and features. The workers were not consulted about the implementation of a new 'managers' tool', although this tool was going to require some participation by them in feeding ABC. Every three months, all 'International Telecom's' employees ${ }^{2}$ have to allocate their time to the activities identified within the ABC system for resource costs to be allocated to activities. This process is supported by the completion of time sheets in Excel. Consultants and management accountants called this process 'PMO'3 [5].

The training meetings were followed by the definition of activities. Before specifying activities, the consultants first identified functions and processes for the whole organisation [3]. This was done with the help of the management accountants. Interviews with employees were then conducted in order to obtain information about the activities performed. People's description of their jobs were obtained, analysed and compared with one another, so that subsequent activities could be identified across organisational boundaries. Work distribution charts were produced summarising the activities performed by employees in each department. Simultaneously, employees were asked about the total time spent on each activity. This helped the consultants to identify activities more accurately [6]. Flow charts were drawn up for each activity performed in 'International Telecom'. Inputs and outputs among activities within the same business process were linked and graphically represented.'International Telecom's' old managerial and cost accounting system had already defined some activities, but they were incompatible with the concept of activity for $\mathrm{ABC}$ - i.e. a homogeneous set of tasks and operations transversal to the organisation. The earlier definition did not cross departmental boundaries, and comprised a very wide range of actions. Nevertheless, the activities defined before helped the consultants to define the activities of the new managerial accounting system. In the old managerial accounting system, some indirect costs were already allocated to products/services through activities. Even though the activities defined before were not very detailed, the existence of a previous system helped the consultants to implement $\mathrm{ABC}$ swiftly. The old managerial accounting system was particularly useful for the consultants in the allocation of resource costs to systems in the operational centres. Some costs incurred in these centres were imputed to submarine cables, satellites and commutation, based on the number of hours performed by employees directly operating these systems. This procedure was maintained by the consultants in the new managerial accounting system. The identification of activities was seen as a very important step in the implementation of $\mathrm{ABC}$ by the consultants and management accountants. They were therefore involved for three whole months in disaggregating functions and business processes in activities. In order to facilitate the definition of activities, cost objects were identified. In the definition of cost objects, 'International Telecom's' business segments were analysed. It was concluded that the international telecommunication services comprised five business segments: (1) fixed telephone; (2) telematics (which include telex, telegraphy, data communication, and store \& 
forward fax); (3) leased capacity (which embrace MID - Direct Ethernet, broadcasting - videocommunications, TV and radio - restoring, and leased circuits); (4) alliances with other operators (as for example with Concert); and (5) other segments (which contain communications through satellite, Inmarsat-C, TCR - telemetry, engineering services in cables and international projects).

After the consultants and management accountants had identified the main priorities of $\mathrm{ABC}$, they decided to calculate costs in five areas: (1) systems (including submarine and terrestrial cables, and satellites. Examples of systems are: Eurafrica; Tagide; Ariane; Columbus; and Americas); (2) tracks (i.e. the path established between operators to support communication. 'International Telecom' - British Telecom', and 'France Telecom - AT\&T' are two examples of tracks); (3) tracks by services and carriers (e.g. British Telecom-Fixed Phones, etc.); (4) carrier (e.g. France Telecom; AT\&T; Telkom South Africa; British Telecom, etc.); and (5) Products/Services. The calculation of costs for the first four areas is easily obtained after calculating costs of products and services, since the latter dimension involves information about the costs of systems, tracks and carriers.

During the identification of activities and the definition of cost objects, the consultants were able to collect the information needed. The consultants believed that all areas were co-operative in providing data, though the two commercial departments (the Consumer Markets Department and Carrier Services \& the Network Planning Department) were the most involved. A dictionary of activities was prepared that defined the scope of each activity. In the dictionary, each activity is named and a short statement of roughly five lines defined it. The aim was to produce a definition of activities that was consistent across the people concerned. The dictionary of activities was particularly useful when people need to complete the PMO [4]. It was distributed to all directors and managers involved in developing $\mathrm{ABC}$ who were accountable for explaining the scope of activities to employees if doubts were raised. After defining 'International Telecom's' main functions, processes and activities, the consultants began identifying cost drivers.

Before, cost drivers were not used to allocate costs to products because activities' costs were imputed to products/services only when they were directly associated with cost objects. The costs of activities not directly related to products/services were registered as indirect costs in the income statement. Direct costs were used as the allocation basis for allocating indirect costs to cost objects. In the new managerial accounting system, on the other hand, cost drivers were defined. Their definition was dependent on the feasibility of obtaining data to support their calculation. After inquiring about the drivers that could enhance the causal relationship between the cost of activities and products/ services, and the availability of information to make calculations, the consultants chose ten drivers.

The next step, after the identification of activities and cost drivers, was the construction of the conceptual model. The architecture of the system was devised by an overseas consultant who was called in at this stage to provide support, due to his experience and knowledge of the telecommunications industry. It was decided with the Board of Directors that the ABC system should be oriented mainly to the commercial areas, and that the production department would be the main department feeding the system [5]. In September 1997, the data collection process began. In December 1997, after writing the software to support the $\mathrm{ABC}$ system, the company was able to generate the first outputs from ABC. The cost data for the first semester of 1997 was

${ }^{4}$ These activities are sub-divided into more detailed activities, which have not been included here for reasons of convenience. obtained, and then discussed by the managers involved in the $A B C$ implementation process. Oros was chosen as the most appropriate computer software to support ABC. Before changing its managerial accounting system to an $\mathrm{ABC}$ model, 'International Telecom' was using the Millennium computer system. It was decided that an SAP application should replace the Millennium system. 'International Telecom's' ABC implementation took about nine months, during which the consultants were in the company on a daily basis. Managers was aware from the beginning of the heavy costs of implementing $\mathrm{ABC}$ so they decided to 'learn' as much as possible about how to operate the $\mathrm{ABC}$ system from the consultants. This attitude seemed to be supported by the consultants, who were apparently committed to transferring all the know-how needed for 'International Telecom' to work the system.

The ABC system implemented in 'International Telecom' is relatively complex. This is because the new managerial accounting system had to provide cost data to regulators, whilst giving managers sound economic information to support pricing and investment decisions and outsourcing strategies. 'International Telecom's' ABC system comprises 115 activities, 71 of which are main activities and 44 supporting ones. The main activities consist of activities oriented to customers ( 35 activities) and to the network (36 activities). Table 1 briefly describes these activities ${ }^{4}$ (Table 1).

'International Telecom' adopted labour hours as first stage drivers, i.e. drivers of resources. The costs of each department are allocated to activities based upon the disclosure of employees' time by activity (PMO). Thus, information provided by employees is crucial to enable the calculation of the cost of activities in 'International Telecom's ABC

\section{Activities:}

\section{1) Main Activities}

1.1) Activities Oriented to Customers

- Defining strategies in Telecommunications business

- Researching and analysing new business opportunities

- Elaborating and controlling marketing plan

- Researching markets and customers

- Developing products and services

- Commercialising products and services

- $\quad$ Billing

- Management of customers' debts

- Maintenance of customers' services

- Assuring the quality of services

1.2) Activities Oriented to Network

- Following telecommunications network technology trend

- Planning network telecommunications

- Managing telecommunications technology development

- Developing and implementing telecommunications network

- Managing the use of network resources

- Operating traffic

- Operating infrastructures

- Restoring telecommunications network

- Preventive maintenance

- Corrective maintenance

2) Supporting Activities

- Developing and managing human resources

- Managing internal communication and information

- Managing financial and physical resources

- Managing the image and the firm's external relations

- Legal support

Source: 'International Telecom's' Dictionary of Activities.

Table 1: 'International Telecom's' ABC Activities. 
system. After the allocation of resource costs to activities, the cost of the latter is attributed to equipment's, systems, tracks, carriers and product/services when related with them. Second-stage drivers (i.e. activity drivers) are used in this allocation process. When activities costs are not related with any of these cost objects, costs are classified as 'common costs ${ }^{5}$ in the income statement. Exhibit 3 shows 'International Telecom's' ABC architecture, and Table 2 lists the second stage drivers, i.e. drivers of activities, selected by the consultants and management accountants (Exhibit 3 and Table 2).

In the new managerial accounting system, direct costs are basically the same as those identified in the previous system. Thus the cost items of 'traffic' (now called costs of 'operator'), 'transmission', 'commutation', 'leased capacities', and rent are maintained. The other direct costs that are new in are the costs resulting from the allocation of activities to cost objects, following ABC implementation. In the present managerial accounting system, direct costs are roughly $75 \%$ of total costs, whereas they were formerly about $70 \%$ of total costs. In 1997, indirect costs were identified as embracing joint costs and common costs. Joint costs are not significant in 'International Telecom's' costs structure. They represented approximately $2.5 \%$ of total costs in 1999 . Joint costs include joint costs of products, joint costs of carriers (costs of carrying traffic for a range of products/services), and the costs of capacity of transmission systems and commutation, which were made available but were not used. Finally, common costs include the costs that the ABC system could not trace directly to cost objects. In 1999, they were about $22.5 \%$ of total costs. Common costs comprise the following items: (1) costs of activities not directly associated with cost objects (or with a family of products); (2) costs of supporting activities which cannot be reallocated to primary activities; (3) costs of capital of the fixed assets that are not directly related to products/services; (4) remunerations and fringe benefits of the Board of Directors, and of personnel temporarily transferred to the telecoms operating in the market; (5) depreciations of fixed assets not directly associated with cost objects (e.g. equipment used by the Board of Directors, telecommunications systems that are not in use, etc.); and (6) extraordinary costs.

Exhibit 4 presents the format of the income statement used in the ABC System (Exhibit 4).

The income statement presented above is used to present cost data for: (1) fixed telephone (coming in, in transit and going out) to

\begin{tabular}{|c|l|}
\hline Driver $\mathbf{1}$ & Number of invoices valued by effort \\
\hline Driver $\mathbf{2}$ & $\begin{array}{l}\text { Number of documents (incoming traffic) * } 80 \%+\text { number of open } \\
\text { positions }>6 \text { months * } 20 \%\end{array}$ \\
\hline Driver $\mathbf{3}$ & Number of invoices per product/service \\
\hline Driver $\mathbf{4}$ & $\begin{array}{l}\text { Number of invoices * } 70 \%+\text { number of open positions }>6 \text { months } \\
\text { * } 30 \%\end{array}$ \\
\hline Driver $\mathbf{5}$ & Setups (Broadcasting - accidental services) \\
\hline Driver $\mathbf{6}$ & Number of processes valued by duration \\
\hline Driver $\mathbf{7}$ & Number of alterations in network valued by the type of service \\
\hline Driver $\mathbf{8}$ & Tracks valued by number of circuits \\
\hline Driver $\mathbf{9}$ & Similar allocation for the respective pseudo-department \\
\hline Driver $\mathbf{1 0}$ & Reallocation according to computer applications/machines DDS \\
\hline
\end{tabular}

Source: Finance and Administration Department - 'International Telecom'.

Table 2: Drivers of Activities.

${ }^{5}$ In a rare number of cases, there are additional costs of activities that are caused by a family of products/services. In this case, the costs of these activities are included in the loss and profit account as 'joint costs of products', thereby being excluded from common costs. This is the case of the costs incurred in the promotion of a whole family of products (e.g. fixed phone).
European countries, US, Canada, Central America, South America, South Africa, Angola, other African countries, and Eastern countries); (2) 'International Telecom's' Green Line'; (3) telematics - telex, telegraphy, fax and data; (4) leased capacity - national, broadcasting, MID, leased circuits, restoring; (5) Inmarsat-C; (6) TCR; and (7) other products/services.

Other income statements that emphasise systems and activities may also be prepared. Their format is similar to that presented above, except that systems and activities are exhaustively listed below lines 2.4.1. to 2.4.4., and 2.6.1. to 2.6.2. of the income statement, respectively.

$\mathrm{ABC}$ data was included in an EIS - Executive Information System. When EIS was introduced in 'International Telecom' it was intended to include only aggregated cost data from the new managerial accounting system. However, because there was no system that could systematically distribute detailed ABC data (except for special reports commissioned by managers), it was decided to provide exhaustive cost data to managers through EIS. In order to facilitate the use of ABC data by all departments, and simultaneously to enhance enthusiasm for the new system in 2000, the management accountants decided to continue preparing managerial accounting reports on an annual basis, as they had done before. The reports management accountants prepare these days comprise: (1) an executive summary of the most relevant events that occurred in 'International Telecom' and its business environment; (2) the presentation of income statements for the whole company, reporting costs/profits for the year in analysis and the previous year; (3) a detailed analysis of each cost item included in the income statement and a comparison with its amount in the previous year. This analysis includes: (a) the presentation of tables reporting the costs of activities by department; (b) profits and costs of automatic telephone by traffic coming in, in transit and coming out; (c) costs of systems (satellites, and submarine cables); (d) costs of commutation and networks; (e) costs of tracks and carriers, amongst other elements; and (4) conclusions.

\section{Conclusions}

The telecommunications industry nowadays operates in a highly competitive market; with the full introduction of competition into the European telecommunications sector, 'International Telecom' has faced huge pressures to improve its competitiveness [2,7]. Its business activities were redefined and focused exclusively on providing international telecommunications, its organisational structure was altered, and its managerial accounting was changed.

'International Telecom's' managers felt that their information systems were not appropriate for the new challenges of the telecommunications market, and that more detailed and accurate costing data was needed. This brought several changes: SAP replaced Millennium; special informational systems directed at executives, such as EIS, were introduced; and $\mathrm{ABC}$ was implemented, amongst other changes.

Firms that are concessionaires for public telecommunications services (and thus accountable for the telecommunications universal service), and are dominant within the market, as is 'International Telecoms', are exposed to a high level of institutional demands [5,8]. These demands are manifest in the requirement for 'International Telecom' to provide detailed information about the quality and the cost of the services and products it provides [5]. Some of the pressures exerted by the regulator and the European Union are related to their need to satisfy market and public opinion that both the 'old' and the 'new' telecommunications firms operate under equal conditions, and that 'true' competition has been introduced $[9,10]$. 
'International Telecom' adopted $\mathrm{ABC}$ not just for generating costing data to assist managers, but also to respond to legal-institutional obligations to provide exhaustive and structured costing data, at any time. The adoption of $\mathrm{ABC}$ enabled the company to legitimise its pricing practices, particularly within the leased circuit and fixed telephone services and interconnection businesses to the regulator and the general public. At the same time, $\mathrm{ABC}$ met the demands of managers seeking managerial tools to help them meet the challenges posed by the full introduction of competition. In sum, the adoption of ABC fulfilled expectations for modernisation in 'International Telecom', created by the reorganisation of EU telecommunications sector.

\section{References}

1. Arthur Andersen (1997) Accounting separation in the context of open network provision, Draft Guidelines Prepared for DG XIII of the European Commission.

2. Bromwich $M$, Hong $C$ (2000) Costs and regulation in the U.K. telecommunications industry, Management Accounting Research 11: 137-165.

3. Cooper R (1990) 'Implementing an activity-based cost system'. Journal of Cost Management (Spring): 33-42.

4. Major M (2007) "Activity-Based Costing and Management: A Critical Review", In Hopper, T., Scapens, R. e Northcott, D. (Eds) Issues in Management Accounting Research, $3^{\text {rd }}$ Edition (London: Prentice-Hall) 155-174.
5. Hopper T, Major M (2007) "Extending Institutional Analysis through Theoretical Triangulation: Regulation and Activity-Based Costing in Portuguese Telecommunications". The European Accounting Review Vol. 16: 59-97

6. Major M, Hopper T (2009) "Activity-Based Costing in the Portuguese Telecommunications Industry" In Lee I (Ed) Handbook of Research on Telecommunications Planning and Management for Business, Illinois: Advances in E-Business Research (AEBR) Book Series, (Western Illinois University): 279-292.

7. Gillett SE, Vogelsang I (Eds) (1999), Competition, Regulation and Convergence: Current Trends in Telecommunications Research (Muhurah, $\mathrm{NJ}$ : Lawrence Erblaum Associates)

8. Kiessling $T$, Blondeel $Y$ (1998) The EU regulatory framework in telecommunications: A critical analysis. Telecommunications Policy 22: 571 592.

9. Commission of the European Communities (1998a) Commission Recommendation of 8 January 1998 on Interconnection in a Liberalised Telecommunications Market: Part 1-Interconnection Pricing, Brussels.

10. Commission of the European Communities (1998b) Commission Recommendation of 8 April 1998 on Interconnection in a Liberalised Telecommunications Market: Part 2-Accounting Separation and Cost Accounting, Brussels. 
Exhibit 1: Income Statement in 'International Telecom' Before the Introduction of ABC

\begin{tabular}{lll}
\hline Description & Year $(\mathbf{N})$ & Year $(\mathbf{N}-1)$ \\
\hline 1. Profits &
\end{tabular}

1.1. Traffic/Leased capacities

1.2. Other profits

Total 1.

2. Direct Costs

2.1. Traffic

2.2. Leased Capacities

2.3. Cost of Transmission

2.3.1. By Submarine Cables

2.3.2. By Satellite

2.3.3. By Radio

2.3.4. Network

2.4. Costs of Commutation

2.5. Other Costs of Operation

2.6. Commercial Costs

2.7. Direct Costs of Capital

Total 2.

3. Profit I (1-2)

4. Indirect Costs

5. Financial Costs/Extraordinary Costs

6. Profit II (3-4-5)

Source: Finance and Administration Department - 'International Telecom’. 
Exhibit 2: Main Events in ABC Implementation

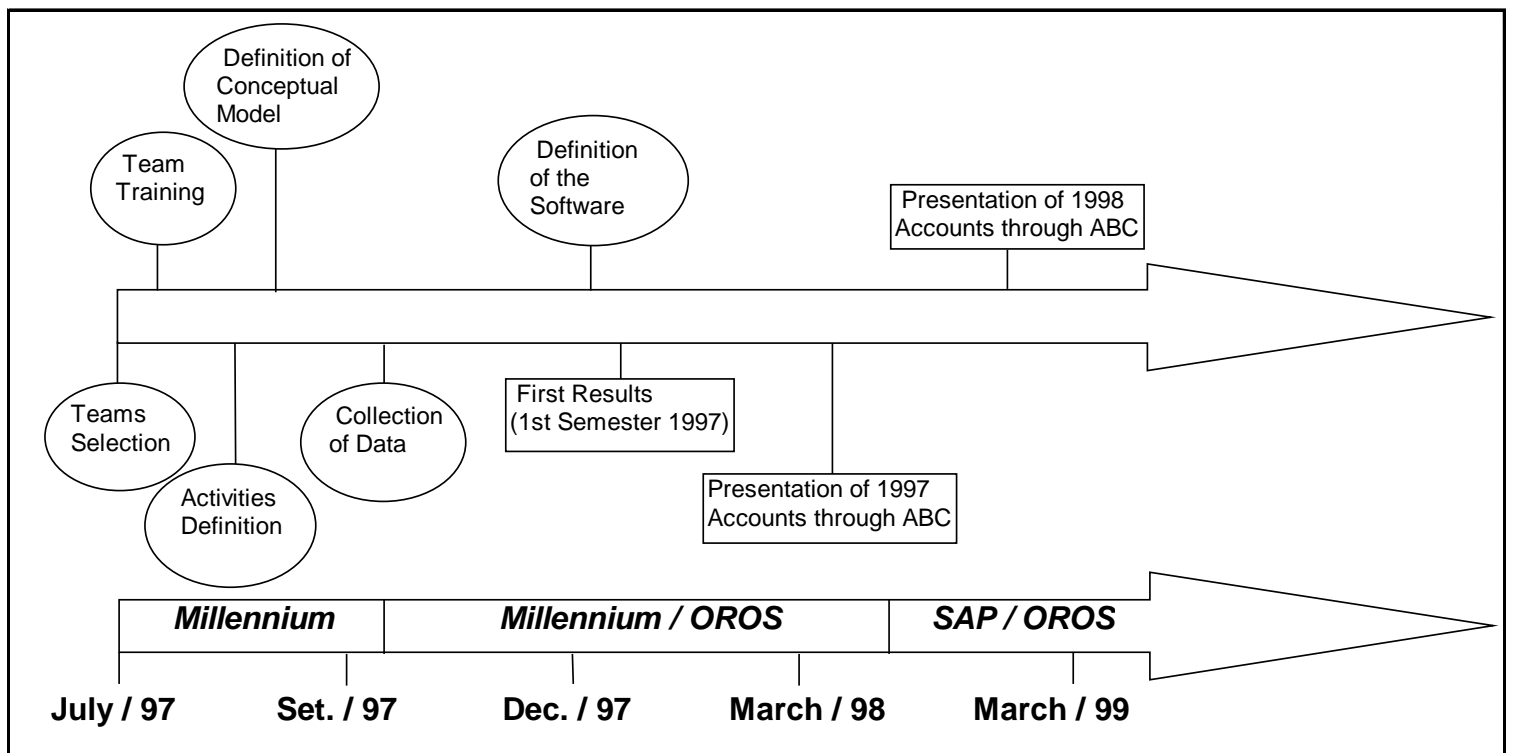

Source: Finance and Administration - 'International Telecom’.

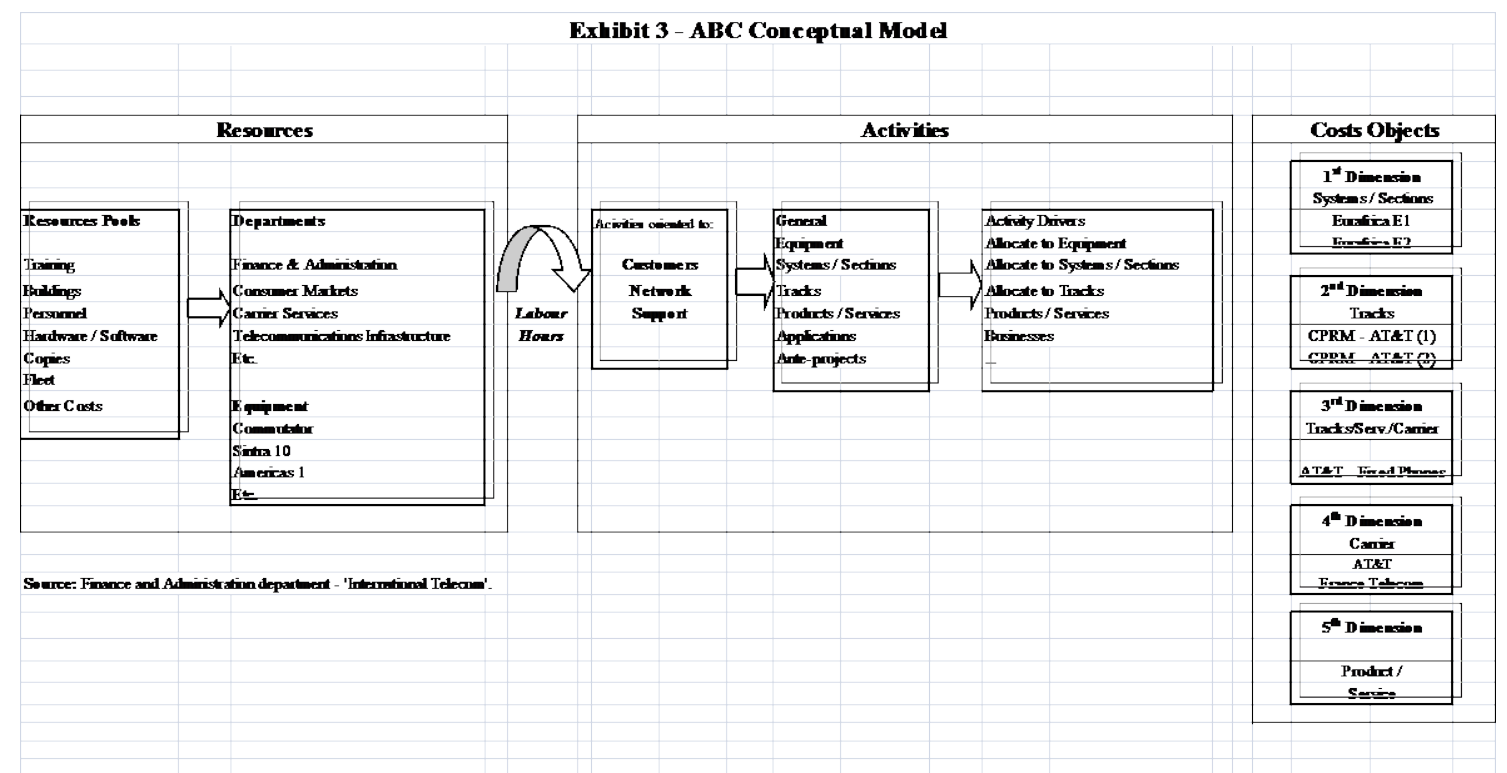

Exhibit 3: ABC Conceptual Model. 
Exhibit 4: Income Statement in the New Managerial Accounting System

\begin{tabular}{lll}
\hline Description & Year (N) & Year (N-1) \\
\hline 1. Profits
\end{tabular}

1.1. Traffic/Leased capacities

1.2. Other profits

Total 1.

\section{Direct Costs}

2.1. Costs of operator

2.2. Leased Capacities

2.3. Rent

2.4. Cost of Transmission

2.4.1. By Submarine Cables

2.4.2. By Satellite

2.4.3. By Terrestrial Cables

2.4.4. Network

2.5. Costs of Commutation

2.6. Other Costs of Activities

2.6.1. Activities Oriented to Customers

2.6.2. Activities Oriented to Network

Total 2.

\section{Joint Costs}

3.1. Joint Costs of Products

3.2. Joint Costs of Carrier

3.3. Capacity Available and Not Used

3.3.1. Transmission

3.3.1.1. By Submarine Cables

3.3.1.2. By Satellite

3.3.1.3. By Terrestrial Cables

3.3.2. Network

Total 3.

4. Common Costs

5. Total of Costs $(2+3+4)$

6. Profit (1-5)

Source: Finance and Administration Department - 'International Telecom’. 